\title{
LA UNIVERSIDAD LATINOAMERICANA Y LA PERTINENCIA DE LOS ESTUDIOS ORGANIZACIONALES PARA SU ESTUDIO
}

\section{RESUMEN}

Las universidades latinoamericanas enfrentan problemáticas inherentes a las especificidades de sus entornos, las cuales buscan responder adquiriendo objetivos, procesos, lógicas y estructuras; cuya interacción las convierte en organizaciones complejas que pueden ser analizadas y comprendidas desde diferentes enfoques. Ante ello, el campo de los Estudios Organizacionales cuenta con diversos aportes y corrientes teóricas que resultan convenientes para el estudio de las universidades y sus problemáticas. En ese sentido, el objetivo del trabajo es analizar la pertinencia de los Estudios Organizacionales para un estudio alterno de las universidades latinoamericanas. Entre los aportes del trabajo está la identificación de algunas de las problemáticas que enfrentan las universidades en América Latina y de los aportes teóricos de los Estudios Organizacionales que pueden ser de utilidad para su estudio.

Palabras clave: Universidad latinoamericana; Estudios Organizacionales; Organización; Educación superior.

\section{A UNIVERSIDADE LATINO-AMERICANA E A RELEVÂNCIA DOS ESTUDOS ORGANIZACIONAIS PARA SEU ESTUDO}

\section{RESUMO}

As universidades latino-americanas enfrentam problemas inerentes as especificidades de seus ambientes, aos quais procuram responder adquirindo objetivos, processos, lógicas e estruturas;

\footnotetext{
1 Profesor-investigador a tiempo completo en el Departamento de Economía asignado a la Universidad Autónoma Metropolitana de Iztapalapa. Doctora en Estudios Organizacionales.

2 Postdoctorante en la Unidad Profesional Interdisciplinaria de Ingeniería y Ciencias Sociales y Administrativas (UPIICSA) del Instituto Politécnico Nacional (IPN).
} 
cuja interação as torna organizações complexas que podem ser analisadas e compreendidas a partir de diferentes abordagens. Diante disso, o campo de Estudos Organizacionais possui diversas contribuições e correntes teóricas convenientes para o estudo das universidades e seus problemas. Nesse sentido, u objetivo do trabalho é analisar a relevância dos Estudos Organizacionais para um estudo alternativo das universidades latino-americanas. Entre as contribuições do trabalho está a identificação de alguns dos problemas enfrentados pelas universidades da América Latina e as contribuições teóricas dos Estudos Organizacionais que podem ser úteis para o seu estudo

Palavras-Chave: Universidade Latino-Americana; Estudos Organizacionais; Organização; Educação superior.

\title{
THE LATIN AMERICAN UNIVERSITY AND THE RELEVANCE OF ORGANIZATIONAL STUDIES FOR ITS STUDY
}

\begin{abstract}
Latin American universities face problems inherent to the specificities of their environments, to which they seek to respond by acquiring objectives, processes, logic and structures; whose interaction makes them complex organizations that can be analyzed and understood from different approaches. Given this, the field of Organizational Studies has several contributions and theoretical currents that are convenient for the study of universities and their problems. In that sense, the objective of the work is to analyze the relevance of Organizational Studies for an alternative study of Latin American universities. Among the contributions of the work is the identification of some of the problems faced by universities in Latin America and the theoretical contributions of Organizational Studies that may be useful for their study.
\end{abstract}

Keywords: Latin American University; Organizational Studies; Organization; Higher education. 


\section{INTRODUCCIÓN}

A pesar de que las universidades pertenecen a un mismo campo y de que realizan relativamente las mismas funciones sustantivas -docencia, investigación y vinculación o extensión universitaria-, cada una tiene elementos y particularidades propios que las diferencian unas de otras. En América Latina se encuentran múltiples significados sobre la universidad, sus representaciones y prácticas. Si bien son producto de una herencia histórica, política y simbólica compartida, las universidades latinoamericanas se gestaron de manera distinta, ya que responden a realidades, demandas, contexto regional e histórico y problemáticas de la región. Entre aquellas se encuentran la globalización de los modelos de educación superior, las concepciones educativas, las estructuras gubernamentales, las concepciones de calidad y la autogestión, por mencionar algunas (ACOSTA, 2018; ORDORIKA; LLOYD, 2014).

Dichas problemáticas expresan las necesidades de cada región, los cual, hace que las universidades latinoamericanas se conformen como organizaciones heterogéneas que adquieren ciertas lógicas inherentes a los entornos en los que se ubican (HOLM-NIELSEN; THORN; BRUNNER; BALÁN, 2005). Ante ello, las universidades se conforman como organizaciones complejas, donde intervienen diversos razonamientos que no se limitan a la lógica instrumental para el cumplimiento de sus objetivos, sino que interviene el carácter simbólico de sus prácticas y la acción de los individuos que la conforman (BARBA; LOBATO, 2012).

En esa línea, la universidad latinoamericana se puede entender como "un complejo constituido por una realidad múltiple y variada. Toda clase de elementos históricos, étnicos, geográficos, y culturales, etc. se mezclan para dar lugar al surgimiento de entidades siempre nuevas y diferentes entre sí" (TÜNNERMAN, 2003, p. 83). Ante ello, argumentan Barba y Lobato (2012), su estudio requiere de múltiples visiones integradas por diferentes disciplinas y metodologías, a partir de las cuales surjan nuevos enfoques interdisciplinarios, integrales y críticos que permitan profundizar en su comprensión, de modo que se reconozca la naturaleza particular y el papel de que juegan en la construcción de la región. 
El campo de los Estudios Organizacionales (EO) es grande, heterogéneo y tiene numerosos enclaves con estilos, orientaciones y creencias diferentes (MARCH, 2007). Uno de sus principales cometidos de acuerdo con Ramírez y Gonzales-Miranda (2019) es dar cuenta de la complejidad de las organizaciones más allá de sus elementos funcionales aproximándose a enfoques alternativos para develar aspectos no considerados como la complejidad, el poder, la cultura, la identidad, entre otros elementos que son característicos de la vida organizacional. Con una tradición que data de la década de los setenta con la constitución del European Gruop for Organizational Studies (EGOS) y el surgimiento de la revista Organization Studies en la década de los ochenta, los EO mantienen un desarrollo, reconocimiento y una divulgación importante en la comunidad académica. Su afianzamiento en América Latina, que, si bien es heterogéneo, ha sido producto de la construcción de redes de cooperación principalmente entre Brasil, Colombia y México que buscan abordar la complejidad de las organizaciones de la región (GONZALES-MIRANDA; RAMÍREZ, 2017).

Lo anterior, hace de los EO un campo pertinente para el análisis y comprensión de las universidades latinoamericanas, ya que cuenta con diversos aportes y corrientes teóricas que permiten caracterizarlas como formas organizacionales que tienen un papel específico en la sociedad (BARBA; LOBATO, 2012). Concebir a la universidad como objeto de estudio de los EO implica analizarla desde "una representación conceptual de la organización y/o de lo organizado, a la cual se adscribe el sujeto, [y que] funcionará como una plantilla sobre lo cual se puede acomodar lo percibido" (CONTRERAS; DE LA ROSA, 2013, p. 19).

De esa forma, los EO permiten estudiar a las universidades a partir de una visión alternativa crítica que las concibe como organizaciones que no sólo buscan la eficiencia (IBARRA, 2001), sino que también sobreviven y se adaptan a partir de una diversidad de objetivos, racionalidades, actores, estructuras, instituciones, entre otros. La interrelación de dichos elementos constituye su complejidad, ambigüedad y adaptación, lo cual no siempre sigue la lógica instrumental que predomina en otro tipo de organizaciones (MONTAÑO, 2012).

En ese sentido, el objetivo del trabajo es analizar cómo los EO contribuyen al estudio de las universidades latinoamericanas. Para ello, el documento se estructura de la siguiente 
manera: primero, se analiza el contexto histórico de la universidad latinoamericana, con la finalidad de contextualizar problemáticas afines a las universidades de la región, atendiendo la recomendación de Ibarra (2006) de dar sentido a la universidad como forma de organización recuperando sus referentes históricos. Para ello se consultan diversas fuentes que permiten ir haciendo un recorrido general que data de la primera universidad instaurada en América Latina hasta los retos que enfrenta la educación superior en la región hoy en día. Se distinguen puntos en común como la herencia colonial, el movimiento de Córdoba de 1918 y la introducción a un contexto globalizado en la década de los noventa.

Posteriormente, se identifican y desglosan algunas temáticas que, sin el ánimo de ser exhaustivos ni caer en generalizaciones, son comunes en el horizonte de la educación superior latinoamericana, estas son: dinámicas, conflictos y tensiones relacionados con su estructura de gobierno, autonomía, legitimidad institucional, gobernabilidad y gobernanza, pertinencia de la educación superior, calidad y evaluación y financiamiento de la educación superior. Se apunta que la selección de estos tópicos se hace a partir de una revisión documental que sin el ánimo de ser exhaustivos o generalizar, busca trazar puntos de encuentro entre las universidades de la latinoamericanas.

En el tercer apartado, se exponen los fundamentos teóricos que dan identidad al campo de los estudios organizacionales, destacando sus principales concepciones sobre la organización y describiendo brevemente algunas de las corrientes teóricas que lo integran, mismas que posteriormente utilizamos para vincularlas con las temáticas previamente identificadas. Se deja en claro que las corrientes mencionadas no abarcan la totalidad del cuerpo teórico de los E0, por ser este un campo siempre en construcción.

En el cuarto apartado, se hace un esfuerzo por definir a la universidad como objeto de estudio de los EO a partir del concepto de Hall (1996) y siguiendo lo postulado por De la Rosa y Contreras (2007). Además, se aborda el ámbito organizacional de la universidad, lo cual permite caracterizarla como una entidad compleja y ambigua. Con base en lo anterior, en el quinto apartado, se proponen algunos de los aportes desde las corrientes teóricas de los EO para el 
análisis de algunas de las problemáticas de las universidades latinoamericanas. Al final, se presentan algunas conclusiones generales.

\section{LA UNIVERSIDAD LATINOAMERICANA}

Las universidades latinoamericanas comparten algunas características en común, como lo son, siguiendo a Tünnerman (2003): el carácter elitista determinado por la organización social y las limitaciones al ingreso; su énfasis profesionalizante y la orientación hacia la investigación y el cultivo de la ciencia; su estructura académica a partir de facultades; el predominio de la cátedra como unidad básica en el proceso de enseñanza aprendizaje; la organización de la docencia a partir de profesiones; la carrera académica y el sistema de concursos de oposición para ocupar plazas docentes; el desplazamiento de la enseñanza por las actividades de investigación en función de que otorgan una ponderación mayor en los sistemas de evaluación; un sistema burocratizado; autonomía para la toma de decisiones en las esferas académica, administrativa y financiera que es diferente en cada país; gobierno democrático con órganos representativos de la comunidad universitaria; participación estudiantil en el gobierno de la universidad; adhesión de la difusión cultural y de la extensión universitaria como parte de las funciones sustantivas; preocupación por los problemas nacionales aunque no exista un vínculo fuerte entre los sectores social y productivos; y, recursos escasos para llevar a cabo sus funciones por mencionar algunas.

No obstante, para comprender el modelo actual de las universidades en América Latina, debemos remitirnos al surgimiento de las primeras instituciones formalmente organizadas en Europa Occidental. La universitas, o bien entendida como el "gremio o corporación de los que enseñan y aprenden, de los maestros y discípulos dedicados al oficio de aprender los saberes" (TÜNNERMAN, 1988, p. 26) sigue la premisa del studium generale, término que indicaba su carácter como centros de instrucción reconocidos donde se albergaba a estudiantes de diversas procedencias. La primera universidad reconocida es la Universidad de Bolonia, donde se impartían cursos de filosofía, teología, matemáticas, astronomía, medicina y farmacia a principios de 1119 y le siguió la de París en 1150. Esto es importante porque de ambas se desprenden dos modelos, el universitas scholarium 
(universidad de los estudiantes) y el universitas magistorioum (universidad de los profesores). El primero surgió del impulso de los alumnos quienes buscaban ser discípulos de juristas reconocidos, mantuvo un gobierno autónomo e influyó a las universidades de la Europa meridional, entre ellas, la Universidad de Salamanca. En el segundo, de origen eclesiástico, los maestros abordaban filosóficamente los temas teológicos por medio de la discusión, estaba sometido a la jurisdicción Papal y se diseminó en las estructuras universitarias de Europa septentrional (ACOSTA, 2016; TÜNNERMAN, 1988).

Cabe destacar que el modelo universitario implantado en América Latina durante la etapa virreinal fue el adoptado por la Universidad de Salamanca, de ahí que la organización universitaria tradicionalmente involucre la participación de la comunidad estudiantil en la forma de gobierno. Por otro lado, el esquema que conjunta la investigación y la docencia surge de las ideas de Wilhelm Von Humboldt tras la fundación de la Universidad de Berlín siguiendo el libertas philosophandi (libertad de pensamiento y de expresión para discutir, enseñar, difundir y publicar (VILLAVERDE, 2017)) en 1810. Se suma el hecho de que el universitas magistorium de la universidad de París se vino abajo cuando, durante la Revolución Francesa, se abolieron las universidades en Francia por considerarse anacrónicas. En ese momento surgen las escuelas especializadas y se reorganiza la Universidad como dependencia del Estado con fines utilitaristas y profesionalizantes. Tales idearios fueron acogidos por las incipientes repúblicas latinoamericanas posteriores a los movimientos independentistas (TÜNNERMAN, 1988).

Ahora bien, la primera universidad instituida en América Latina fue la de Santo Domingo (República Dominicana) en 1538 la cual era de orden clerical y es considerada como el precedente de las universidades privadas religiosas. Por otro lado, las universidades de Lima y México fundadas en 1521 siguieron los estatutos de la escuela de Salamanca y fueron imitados por otras instituciones del continente (TÜNNERMAN, 1988). El balance de Tünnerman (1988) sobre la universidad colonial, es que se fundó para atender a los intereses de los grupos dominantes, tradición aún perceptible en las universidades latinoamericanas. Para Acosta (2016), la aparición de las universidades en esta etapa significó la consolidación 
de espacios privilegiados para clases y estratos sociales específicos, cuya finalidad era la formación de un funcionariado eclesiástico y civil.

Tras los movimientos independentistas, la universidad mantiene su carácter elitista, encaminada a la formación de servidores públicos y alejada del interés por la ciencia (TÜNNERMAN, 1998). Aparecen dos universidades que se convierten en los modelos clásicos a replicar en el continente, estas son: la Universidad de Chile fundada en 1843 por Andrés Bello y la Universidad Nacional de México erigida por Justo Sierra en 1910, siendo la más influyente la primera, la cual transitó de formar clérigos a preparar funcionarios del Estado, en este caso abogados, quienes jugaron un importante rol en la estructuración de las nacientes repúblicas (TÜNNERMAN, 2003).

El movimiento de Córdoba, Argentina en 1918 es uno de los primeros cuestionamientos sobre la organización universitaria y su finalidad y se le considera como el punto de partida de la reforma que perdura hasta hoy. Las universidades "estaban lejos de responder a lo que América Latina necesitaba para ingresar decorosamente en el siglo XX y hacer frente a la nueva problemática planteada por los cambios experimentados en la composición social debido a la urbanización, la expansión de la clase media y la aparición de un incipiente proletariado industrial" (TÜNNERMAN, 1998, p. 61). Este levantamiento social se realizó por la clase media emergente, quienes veían a la universidad como un instrumento que permitiría su ascenso político y social y emprendieron la lucha contra la clase oligárquica, denunciando el atraso científico de la universidad y el carácter elitista de su gobierno (MARSISKE, 2010; SAMACA; ACEVEDO, 2011; TÜNNERMAN, 2003).

En el pliego petitorio expresado en el Proyecto de Ley Universitaria y Bases Estatutarias derivado del primer congreso estudiantil en 1918 convocado por la Federación Universitaria Argentina (FUA), son fundamentales los reclamos sobre la autonomía y gobierno universitario, los cambios en la enseñanza y métodos de contratación docentes y la proyección política y social de la universidad. A partir de este momento, la autonomía universitaria se erige como un muro de contención para limitar la intervención del Estado y se instituyéndose como un elemento que caracteriza a las universidades. El movimiento de 
Córdova paso de ser un levantamiento local a ser un fenómeno latinoamericano que perseguía la construcción de una nueva universidad. Se reconoce la importancia histórica del suceso por ser un hito en la lucha por la consolidación de un modelo de universidad que se ajuste a las demandas del contexto social, donde predomine la creación de conocimientos y no una mera transmisión con fines de adoctrinamiento para el mercado laboral. El impacto de este acontecimiento se disemina en Latinoamérica en los años subsecuentes (DÍAZ, 2004; MARSISKE, 2010; NOSIGLIA, 2018; SAMACA; ACEVEDO, 2011; TÜNNERMAN,1998, 2003).

Durante los sesenta, emergen diversos procesos de movilización y radicalización estudiantil que marcaron la coyuntura en la que se redefinió el rol de la universidad. Aunque cada uno mantiene su especificidad, de manera general tienen como marco contextual la masificación de la educación superior entre los hijos de trabajadores, obreros y la clase media, lo que trajo consigo la escasez de cupos para estudiantes, las restricciones presupuestarias y la inadecuación de las estructuras existentes para atender las demandas. En el rubro social y económico, el antecedente es la urbanización alentada por el incremento de la población y la migración campo-ciudad y el aumento de la desigualdad en la distribución de la riqueza donde los sectores populares quedan al margen en condiciones de precariedad. En el ámbito universitario se amplió la oferta de carreras orientadas al sector productivo ante la reciente industrialización en los países de la región. Las demandas estudiantiles durante esta década se centraron en la falta de democratización en la esfera educativa y detonaron la expresión combativa ante el autoritarismo del régimen que, con violencia, contenían a la comunidad universitaria. Son característicos los movimientos de Brasil, México y Argentina (DONOSO, 2018; LUCIANI, 2019).

En el primero, los estudiantes fueron criminalizados por delitos políticos con la ley 477, lo cual disolvió temporalmente en 1969 a la Unión Nacional de Estudiantes (UNE), quienes trabajaron por construir una universidad abierta en la que existiera libertad de pensamiento y cátedra. En México, los hechos acontecidos el 2 de octubre de 1968 en la plaza de Tlatelolco buscaron disgregar el movimiento y terminaron con una masacre de centenas de estudiantes, dejando una herida muy grande en la historia del país. En Argentina, los 
acontecimientos del Cordobazo radicalizaron la política de la sociedad y articularon a los estudiantes con la clase obrera; en el ámbito universitario, se suscitaron demandas relacionadas con problemáticas de la realidad institucional que originaron una coyuntura en 1971 caracterizada por la agudización de los enfrentamientos entre estudiantes y fuerza pública (LUCIANI, 2019; SAMACA; ACEVEDO, 2011).

La década de los noventa es otro punto neurálgico en la conformación del modelo universitario latinoamericano. En este periodo, se inician distintas reformas de corte neoliberal para tratar de subsanar la crisis económica del decenio anterior y entrar en la dinámica de la globalización (ORDORIKA; LLOYD, 2014). Las medidas consistieron en la eliminación del proteccionismo comercial, la liberalización de los mercados financieros y la reducción de la intervención del Estado en la economía. Se suprimieron las políticas de subsidio y de fomento industrial, se elimina la protección comercial y los mercados se abren a la competencia internacional. Las reformas si bien lograron reducir la inflación y el déficit fiscal, no cumplieron con mantener un crecimiento económico alto y sostenido (MORENO; RUIZ, 2009). Esto se señala dado que "la concepción, ideas o creencias que sustentan la acción y las estrategias de los gobiernos latinoamericanos en el campo de la educación superior universitaria en los años noventa, ellas no pueden desligarse del "espíritu de la época" que dominó el mundo de las políticas públicas y el desempeño del Estado a lo largo de esa difícil época" (ACOSTA, 2002, p. 47).

Las reformas universitarias en América Latina durante dicho periodo fueron producto de la combinación entre relaciones de poder, políticas públicas y cambios institucionales. Surgen temas como la evaluación, calidad, diversificación, eficiencia y competitividad (ACOSTA, 2002) a manera de combatir los problemas de financiamiento, gestión, organización y rendimiento académico que se manifestaban en las universidades de la región. Emergió la presión internacional de los organismos internacionales para generar transformaciones. Si bien se buscó el alejamiento del Estado, de forma contradictoria las reformas dieron lugar a la creación de organismos de evaluación y acreditación en países 
como Brasil, Colombia, Cuba, Chile, Costa Rica y México, que, para garantizar la calidad del sistema educativo, exigieron la participación del Estado (VILLANUEVA, 2010).

Entre las recomendaciones dispuestas se señala la reducción del presupuesto estatal a las entidades que no mostraran una alta eficiencia. En el caso de las universidades, el reto fue medir la rentabilidad social de la educación superior. La problemática recayó en que el financiamiento se mantuvo estable, pero en esa década la matrícula se incrementó de forma exponencial, por lo que se instó a las organizaciones a lograr una gestión más eficiente o a conseguir recursos por sus propios medios. Como consecuencia social, se extendieron las brechas entre quienes tuvieron acceso a la educación superior, sea en el sector público o privado - el cual tuvo una etapa de crecimiento importante de absorción de demanda excepto en Argentina y Uruguay- y quienes no (VILLANUEVA, 2010). En suma, se hace énfasis en la rendición de cuentas, la evaluación en todos los niveles, la flexibilización y la vinculación de la universidad con el mundo empresarial, lo que hace que las universidades tengan, por un lado, la función de crear conocimiento y, por otro, capacitar a la fuerza de trabajo para el mercado global, lo que ha trastocado su identidad (ORDORIKA; LLOYD, 2014; RHOADES, et al., 2004).

En la actualidad algunos de los retos que enfrentan las universidades en América Latina continúan siendo la disminución de subsidios estatales para la educación la ciencia y la cultura; la expansión de las instituciones y las matrículas privadas; la descentralización del gasto universitario; la regulación del acceso, la permanencia y el egreso; y, la creación de comisiones de evaluación y acreditación para homogeneizar y vigilar el funcionamiento de las instituciones de educación superior de cada país. Tales directrices han buscado regular el conjunto universitario de Latinoamérica y atender problemáticas afines como el incremento de la cobertura, la reglamentación de las instituciones privadas, y la implementación de criterios comunes a la plantilla curricular y administrativa, no obstante, se debe reconocer que las instituciones en América Latina discurren entre la mercantilización educativa y las prácticas de mercado en los sistemas académicos (ORDORIKA; LLOYD, 2014).

Son particulares también las desigualdades educativas en Latinoamérica, donde se vuelve prioritario brindar atención a los diversos grupos sociales y étnicos de la población; 
mejorar las condiciones para el acceso a la educación superior en pro de mejorar los indicadores de cobertura y eficiencia terminal; analizar a fondo la pertinencia de la educación superior ante el escenario de la mercantilización educativa; mejorar los niveles de formación docentes; valorar la incorporación de contenidos curriculares orientados a las demandas de la sociedad del conocimiento; fomentar la incorporación de las nuevas tecnologías de la información y la comunicación a los procesos pedagógicos de enseñanza-aprendizaje; y, reflexionar sobre la aplicación de políticas supranacionales homogéneas que refieren realidades distintas a las existentes en cada país e incluso, pensando en una micro escala, en las comunidades (FERNÁNDEZ; COPPOLA, 2013).

\section{TEMÁTICAS DE LAS UNIVERSIDADES LATINOAMERICANA}

Como se ha podido identificar en el apartado anterior, las universidades en América Latina han adquirido características específicas y enfrentado algunas problemáticas en común propias de su desarrollo histórico (HOLM-NIELSEN et. al., 2005). Latinoamérica representa una heterogeneidad de espacios universitarios donde se puede identificar un marco contextual compartido. La propuesta en este documento es identificar algunas tendencias que, sin el ánimo de ser exhaustivos o establecer generalizaciones, ayuden a describir a las universidades de la región. Dichas temáticas se plantean bajo el supuesto de que las universidades latinoamericanas tienen puntos de contacto y a su vez de fragmentación (FERNÁNDEZ; CÓPOLA, 2013). Una vez descritas, se da paso a las aportaciones del campo de los EO.

\section{DINÁMICAS, CONFLICTOS Y TENSIONES RELACIONADOS CON SU ESTRUCTURA DE GOBIERNO}

Como argumenta Acosta (2016), las universidades son espacios donde confluyen de manera conflictiva la lógica del saber y la lógica del poder. Esto deja ver que existen entramados de antagonismos y tensiones que recorren a la universidad. Entre ellos, están incluidas las determinantes de su estructura y la dinámica de su gobierno, los esquemas de gobierno predominantes, su organización académica y administrativa, la búsqueda de 
gobernanza en sus acciones, las relaciones políticas internas, entre otros (ACOSTA; ATAIRO; CAMOU, 2015; ACOSTA, 2018; TÜNNERMAN, 2011; ACOSTA, 2016).

El movimiento de Córdoba en 1918 otorgó gran importancia a la participación estudiantil y al establecimiento del cogobierno, encabezado por comisiones entre alumnos, profesores y egresados, quienes toman decisiones sobre la política de la universidad en lo referente a presupuesto, personal y currículo (WAGGONER, 1974). La actual concreción de este espacio de gobierno democrático en el que existen órganos colegiados de representación importantes para la toma de decisiones es relevante porque permite reflexionar sobre las tendencias de crecimiento, diferenciación y complejidad institucional (ACOSTA; ATAIRO; CAMOU, 2015). Una de las principales críticas es que los gobiernos de las universidades latinoamericanas se conforman por estructuras tradicionales que responden a modelos externos y no a modelos propios que consideren las características de las universidades regionales. Así, las estructuras de gobierno son rígidas, burocratizadas, con conflictos entre grupos internos y tensiones de poder con las autoridades externas (RAMÍREZ, 2019).

\section{AUTONOMÍA}

La autonomía universitaria ha sido un pilar en las universidades públicas de América Latina y se encuentra en constante evolución (ACOSTA, 2016, 2018, ACOSTA; ATAIRO; CAMOU, 2015). Autores como Tünnerman (2011), señalan que uno de los mayores riesgos que corre la autonomía universitaria en América Latina, es la influencia de grupos de poder afiliados a partidos políticos que impiden el desempeño de su función crítica excluyendo al alumnado de cultivar la conciencia crítica y soslayando la cultura democrática. La recomendación del autor es repensar la autonomía universitaria en términos de su participación en el escenario nacional sin perder su eje de independencia. Para Jiménez (2007), la autonomía se enfrenta al reto de frenar una intervención contraproducente del Estado y de las empresas en sus asuntos internos, pero al mismo tiempo, esto evidencia la necesidad de generar una relación de cooperación con los grupos de poder para proponer nuevos paradigmas que contribuyan al desarrollo social. 
Otro punto crucial en el panorama actual de la autonomía en las universidades de América Latina tiene que ver con el financiamiento de las universidades públicas. Se considera que, al depender económicamente del Estado, puede desempeñar su autonomía académica y de gobierno en total libertad, pero no sucede lo mismo con la autonomía financiera. En este sentido, se le ve como una autonomía limitada que la obliga a rendir cuentas a las autoridades federales, cumplir con los proyectos educativos que se le encomienden y responder a la normatividad nacional de la que depende su presupuesto (DÍAZ, 2004). Ante el escenario de crisis en el que cada vez se cuenta con menor financiamiento, la autonomía se encuentra en un punto en que debe redefinirse ante la necesidad de las universidades de buscar recursos de forma externa vinculándose con otros sectores de la sociedad.

\section{LEGITIMIDAD INSTITUCIONAL, GOBERNABILIDAD Y GOBERNANZA}

De acuerdo con Acosta, Atairo y Camou (2015), la legitimidad institucional, la gestión y la búsqueda de gobernanza son temáticas importantes que caracterizan a la universidad latinoamericana actual. Los autores definen a la gobernabilidad como un equilibrio dinámico entre las demandas de los actores universitarios y la capacidad de darles atención de manera legítima y eficaz. Por otra parte, la gobernanza universitaria confiere las reglas del juego para mediar las relaciones de poder entre los actores. La legitimidad, por otro lado, es uno de los grandes retos de la universidad en el presente, especialmente de la latinoamericana, por su calidad como pilares del pensamiento crítico, lo cual se torna difícil debido a las presiones que ejercen los modelos de educación mercantilista que anteponen la ganancia económica a la educación integral.

Situaciones como esta extinguen la legitimidad de la universidad como bastión del conocimiento, aunado a la intervención de autoridades en continuas faltas a su autonomía (Ramírez, 2019). Esto dificulta su autogestión técnica y política, así como el establecimiento de gobiernos basados en modelos de gobernanza que respondan a las necesidades educativas de cada región (GACEL-ÁVILA; JARAMILLO; KNIGHT; DE VIT, 2005). 


\section{PERTINENCIA DE LA EDUCACIÓN SUPERIOR}

La pertinencia de la educación superior es entendida como la necesidad de que las universidades se sintonicen con el entorno que les da lugar y con sus dinámicas. En este entendido, la universidad latinoamericana, ha atravesado por diversas transformaciones que, pese a recuperar elementos de otras latitudes, se han adaptado al contexto y demandas sociales, políticas y económicas. En la actualidad, la pertinencia se ha convertido en un referente en el diseño de políticas gubernamentales y traza vínculos entre el sistema productivo y el universitario en el marco de la sociedad del conocimiento, (ACOSTA; ATAIRO; CAMOU, 2015; DIDRIKSSON, 2015; HERNÁNDEZ; MARTUSCELLI; MOCTEZUMA; MUÑOZ, 2015).

La pertinencia se consigue mediante la participación de la universidad a través de sus actores, en la vida social, económica y cultural de la sociedad, siendo una relación bidireccional. Actualmente, la educación superior se ha convertido en un factor que posibilita el crecimiento económico y el progreso social de los países, siendo preponderante la inversión en educación. Empero, la vinculación de la universidad exclusivamente con el sector empresarial es una visión limitada, dado que se deben generar puentes de cooperación con el sector productivo, gobierno y sociedad de modo que la pertinencia sea vista de forma integral en correspondencia con los proyectos objetivos y demandas de las instituciones; en el sentido pedagógico de la educación y las nuevas modalidades que encaminan a la innovación; en cuanto a la formación del estudiante en relación con valores, ética social; en conexión con el sistema educativo y el desarrollo científico y tecnológico (MALAGÓN, 2003)

\section{CALIDAD Y EVALUACIÓN}

El tema de la calidad es uno de los más abordados en la región, aunque no se tenga cohesión en las variantes del término. Surge en América Latina ante el contexto de la crisis económica en la década de los ochenta. A nivel de política educativa, se le vincula con la pertinencia, y con la equidad siendo inseparables (TÜNNERMAN, 2011). Se reconoce la influencia de las recomendaciones de los organismos internacionales en la definición de políticas supranacionales para América Latina, como el Banco Mundial, la Organización para 
la Cooperación y Desarrollo Económico (OCDE) y el Banco interamericano de Desarrollo (BID). Por ejemplo, para la UNESCO, la calidad se define como una función del Estado, cuyo objetivo es garantizar el derecho a la educación de las nuevas generaciones, lo anterior, a partir de un conjunto de acciones que provean a las escuelas, docentes y estudiantes de los recursos necesarios para fortalecer la calidad de los aprendizajes y la equidad del sistema (INEE-IIPE UNESCO, 2018).

Como se ha resaltado, los sistemas nacionales de educación superior latinoamericanos se caracterizan por ser heterogéneos, lo que a su vez demarca una variedad de orientaciones acerca de la calidad. En la región, los sistemas existentes tienen como finalidad el mejoramiento o promoción de esta mediante la acreditación de programas de estudio, la acreditación institucional o la medición de los resultados de aprendizaje. El grado de desarrollo de los sistemas de aseguramiento de calidad varía entre naciones, sin embargo, se destaca que países como Brasil, Chile, Colombia y México tienen un rol histórico en la formulación y ejecución de políticas de educación superior en la región (PÉREZ, 2004; PIRES; LEMAITRE, 2008). El análisis de Pires y Lemaitre (2008) subraya el hecho de que la evaluación y la acreditación de la calidad han pasado de ser una recomendación teórica a una política efectivamente implementada en América Latina a partir de la década de los noventa. La evaluación se ha transformado de modo que hoy en día se enfrentan cuestiones como la pertinencia de criterios unificadores que no consideran las diferencias entre sistemas ni recuperan las voces de los actores y, el hecho de que los mecanismos existentes no solo sean medios de control o de garantía externa de calidad, sino que fomenten procesos de actualización y mejora continua.

\section{FINANCIAMIENTO DE LA EDUCACIÓN SUPERIOR}

Para Acosta (2018), una de las grandes problemáticas de las universidades públicas en América Latina es el asunto financiero. Particularmente, las universidades de la región están sometidas a restricciones en la distribución de los recursos por parte de los gobiernos estatales o nacionales como principales financiadores y siendo quienes establecen las predisposiciones sobre cómo deben ser distribuidos (RAMÍREZ, 2019). La dinámica a partir 
de la cual se estructuró la educación superior en Latinoamérica fue sobre la base de un sector de instituciones públicas y otro de instituciones de élite. Durante la etapa de la masificación, se generó un desajuste entre la oferta y la demanda provocando una escasez de recursos financieros en el sector público (RAMA, 2018). Se plantearon algunos mecanismos para resolver el desequilibrio tales como el cobro de matrículas a manera de generar obtener recursos y se diseñaron exámenes de admisión para reajustar la oferta y la demanda. En otros casos se flexibilizaron las condiciones de ingreso permitiendo mayores estudiantes por aula incidiendo en los niveles de calidad para reducir el presupuesto por alumno. Como resultado, se diferenciaron las instituciones de educación superior favoreciendo la aparición de organizaciones de diferentes costos, calidades y finalidad.

A principios de 2000, las políticas en educación superior marcaron un aumento en el financiamiento al considerarse la educación como un bien público, incrementándose la matrícula en el sector público y por ende la cobertura. Se aumentó el porcentaje del gasto educativo en países como Argentina, Bolivia, Chile, Costa Rica, Cuba, Ecuador, México, Paraguay, Perú, Guatemala y Uruguay, resultando en poco más del 1\% del PIB destinado a la educación superior pública (RAMA, 2018). "Las nuevas dimensiones de la escala de la educación superior están planteando diversas problemáticas para seguir dotando de recursos financieros que permitan continuar el crecimiento de la educación superior en el contexto de los nuevos escenarios económicos, que parecen mostrar un menor nivel de crecimiento futuro en las economías latinoamericanas" (RAMA, 2018, p.8).

\section{LOS ESTUDIOS ORGANIZACIONALES Y SUS APORTES TEÓRICOS}

Los Estudios Organizacionales se han integrado como campo de análisis organizacional que busca estudiar los diversos tipos y formas de organización, a partir de múltiples disciplinas como la psicología, sociología, ciencias políticas o economía, cuyo diálogo y complementación permiten explicar las realidades organizacionales y sociales (GARCÍA-DE-LA-TORRE, 2017). Ante su carácter transdisciplinario, los EO se han distinguido por la multiplicidad de enfoques y pluriparadigmas que permiten construir respuestas 
alternativas al enfoque positivista de la Teoría de la organización (GONZÁLEZ- MIRANDA; RAMÍREZ, 2017).

Así, los EO se han consolidado como un campo alterno en el estudio de las organizaciones que, a partir de conversaciones entre académicos y vocabularios o gramáticas diferentes, establecen debates acerca de las temáticas organizacionales (CLEGG; HARDY, 1996a, 1996b). En esa línea, uno de los principales aportes de este campo de estudio es su concepción de las organizaciones como espacios que los seres humanos construyen y donde plasman sus subjetividades (BARBA, 2013).

Ante ello, las organizaciones lejos de concebirse como entes perfectos se entienden como procesos complejos que constantemente se reconstruyen (GONZÁLEZ- MIRANDA; RAMÍREZ, 2017). Por lo cual, desde los EO el concepto de organización hace referencia a las construcciones sociales caracterizadas por la complejidad conformada por la interrelación de diversos factores como la ambigüedad, el conflicto, los símbolos, las diversas racionalidades (BARBA, 2013), la cultura, las instituciones, el aprendizaje, las varias formas de organización (DE LA ROSA, 2002), la confrontación, el conflicto, la ambigüedad y el poder (RAMÍREZ; VARGAS; DE LA ROSA, 2011).

Para estudiar aquellos elementos, el campo de los EO se integra de diversas corrientes de pensamiento que brindan aportes teóricos adecuados para una comprensión integral. Como argumenta Gonzales-Miranda (2020), el campo ha sido lo suficientemente flexible para incorporar distintos cuerpos teóricos que se enlazan tanto con los intereses académicos, como con el aspecto central que son las organizaciones, incorporándose temáticas emergentes como las que se han desarrollado en América Latina. Para la construcción de esta sección, se recuperan el poder, el análisis estratégico, las redes organizacionales, la ambigüedad, la ecología organizacional, el nuevo institucionalismo sociológico, la antropología de las organizaciones, el análisis posmoderno, el psicoanálisis, la cultura, el aprendizaje y el conocimiento organizacional, el cambio organizacional y los estudios de género, sin que estas condensen la totalidad del cuerpo teórico de los EO, dejando abierta la posibilidad de incorporación de otras temáticas. 
De esta manera, los estudios realizados sobre el conflicto y las relaciones de poder retoman a este último como un conjunto de relaciones complejas que están limitadas por las estructuras de la organización. Los actores continuamente buscan modificar y utilizar para su conveniencia dichas estructuras (CROZIER, 1973). Así, para los EO, el poder es una característica fundamental en las organizaciones, las cuales son vistas como arenas de lucha donde prevalece el conflicto y no la estabilidad ni el orden (CLEGG, EN HICKSON, 1988)

El estudio del poder en los EO se relaciona con el estudio del análisis estratégico, el cual refiere al estudio de la acción de los integrantes de una organización y a su capacidad estratégica para modificar las estructuras a través de determinados juegos de poder que funcionan como mecanismos de regulación. Desde la corriente del análisis estratégico, los juegos de poder son los que dan sustento a la acción organizada de los actores y definen la lógica que se establece en toda la organización. Entonces, ésta se constituye como un sistema de acción concreto. Este constructo teórico hace referencia a los sistemas donde el ejercicio del poder es el medio estratégico para generar nuevas reglas o estructuras que permiten continuar con los juegos de cooperación y conflicto (CROZIER; FRIEDBERG, 1990).

Las redes de organizaciones es otro de los temas significativamente abordado en los EO, tan es así que puede considerarse una corriente de pensamiento en este campo de estudio (CONTRERAS; DE LA ROSA, 2013). Ésta tiene sus comienzos con los estudios de Evan (citado en BARBA; SOLÍS, 1997) donde se desarrolló el término organization set, el cual hace referencia a las redes de organizaciones. Dichos aportes son pertinentes para analizar a las organizaciones a nivel macrosocial, específicamente en cuanto a las relaciones que aquellas tienen con el medio ambiente. Desde esta visión de redes, el contexto es organizacional pues está configurado por organizaciones y redes de organizaciones (BARBA, 2013).

El estudio de la ambigüedad en la organización es uno de los elementos que mayor aportan a la identidad de este campo (BARBA, 2013) pues se estudia como un elemento inherente a las realidades organizacionales y no como un elemento que debe ser erradicado (COHEN; MARCH; OLSEN, 1972; COHEN; MARCH 1974; MARCH; OLSEN, 1976). Desde este enfoque, la ambigüedad incluso puede ser positiva en las anarquías organizadas, 
organizaciones donde los objetivos, medios de implementación y tomadores de decisiones son confusos, inestables y condicionados por las limitaciones de entorno (MARCH; OLSEN, 1976).

En otro orden de ideas, la ecología organizacional explica por qué ciertas organizaciones pueden sobrevivir y multiplicarse, cuando otras perecen. Esta corriente de pensamiento tiene sus orígenes en los postulados de la selección natural de Darwin. La premisa central dicta que las organizaciones sobreviven debido al ambiente en el que se encuentran; es un enfoque evolutivo donde las transformaciones de las organizaciones y su sobrevivencia se debe a los cambios constantes que experimentan (BARBA; SOLÍS, 1997).

Pasando a otro aspecto, los fundamentos teóricos del nuevo institucionalismo pueden separarse en dos vertientes. A nivel macro, se concibe a la estructura organizacional como resultado de una serie de mitos racionalizados que dan legitimidad a la organización, su desempeño y eficiencia. Cuando las organizaciones adoptan los mismos mitos, se ven sometidas a procesos de isomorfismo coercitivo, mimético o normativo, por los cuales entran en una homogeneidad estructural y conforman un campo organizacional. En el nivel micro, se encuentran los procesos de institucionalización sucedidos en las relaciones interpersonales dentro de un contexto sociocultural, aquí se toma en cuenta cómo las prácticas organizacionales se transmiten entre los actores (DE LA ROSA, 2002).

Otra de las corrientes de los EO es la antropología de las organizaciones, la cual tiene su foco de análisis en el individuo, concebido como un ser humano complejo que establece relaciones de diversa índole con su medio ambiente y con las organizaciones a las cuales pertenece (CHANLAT, 1998; CHANLAT; BÉDARD, 2000). Así, los preceptos de esta corriente rescatan elementos propios de la condición humana, tales como el mundo simbólico, la historia, la ética, la afectividad, la capacidad transformadora, los grupos, la experiencia y el conocimiento (CHANLAT, 1998).

Una temática más es el estudio de las organizaciones postmodernas, que refiere a las organizaciones con estructuras flexibles, cuyas principios se sustentan en las tecnologías de nueva generación (HEYDEBRAND, 1989). Esta corriente de pensamiento surge a raíz de la 
diferencia establecida entre modernidad y posmodernidad (CLEGG, 1990). Así, mientras la organización moderna representa el tipo ideal de la burocracia weberiana, la organización posmoderna contradice la jerarquización, la división estricta de funciones y la rigidez de las reglas (HEYDEBRAND, 1989).

Otro tema es el análisis postmoderno de las organizaciones, que consiste en el estudio organizacional a partir de narrativas flexibles que se enfocan en situaciones como las luchas de poder, el cambio sociotécnico y la transformación social. Dichas narrativas se basan en discursos y teorías anteriores para generar nuevos aportes que den explicaciones y concepciones alternas de las organizaciones actuales (REED, 1993). Así, desde esta corriente de pensamiento, la organización es concebida como un espacio donde se determinan formas y prácticas discursivas que establecen las condiciones materiales y sociolingüísticas que dominan en contextos específicos; a través de elementos como el poder, el control y la disciplina (REED, 1998; WITTEN, 1997).

Por otro lado, el psicoanálisis en las organizaciones se enfoca en las relaciones que se establecen entre la organización y el individuo. Tales estudios se basan en los aportes de Enriquez (2007), Pagés, Bonetti, De Gaulejac y Descendre (1979) y Aubert y De Gaulejac (1993), a partir de los cuales se establece que el inconsciente es un campo de contradicción y que la relación organización- individuo se basa en las estructuras establecidas en el inconsciente de sus integrantes.

La cultura en las organizaciones identifica los elementos simbólicos que dan sentido a una organización, entre ellos se encuentran las diversas expresiones sociales y las redes de significados que los integrantes traen de sus entornos hacia el interior de la organización (SMIRCICH, 1983). Dicha corriente analiza la vertiente de la cultura corporativa como un mecanismo utilitario para lograr la eficacia a través del uso de valores o rutinas que los dirigentes de la organización establecen deliberadamente (DEAL; KENNEDY, 1985; SCHEIN, 2004). Por otra parte, la cultura también puede ser entendida como una metáfora que expresa los elementos arraigados en la informalidad de la organización, por ejemplo, el lenguaje cotidiano (BARBA; SOLÍS, 1997). Aunado a ello, la cultura en las organizaciones 
también es analizada como un espacio influenciado por los rasgos culturales específicos de cada región (HOFSTEDE, 1997).

El aprendizaje y conocimiento organizacional refieren a la capacidad de las organizaciones para emprender nuevos procesos de aprendizaje y crear conocimientos propios, o adoptar conocimientos de otras organizaciones (ARGYRIS; SCHÖN, 1978). Desde este enfoque se argumenta que el aprendizaje es el medio para la innovación, pues se parte del conocimiento tácito de los integrantes para comenzar procesos cuyas fases son socialización, exteriorización, interiorización y combinación. A través de dichos procesos se produce el conocimiento explícito o propio de la organización (NONAKA; TAKEUCHI, 1999).

En otro orden de ideas, el cambio organizacional hace referencia a los procesos de transformación por los cuales atraviesan las organizaciones. Esta corriente se basa en los aportes de Van de Ven y Poole (1995), quienes establecen ciertos preceptos teóricos para analizar cómo sucede el cambio organizacional. Aquellos son el ciclo de vida, la teleología, la dialéctica y la evolución; los cuales proponen diversas causas que pueden impulsar o resistir los procesos de cambio, por ejemplo, el conflicto o las transformaciones del entorno y su cultura (GREEN, 1998; CHREIM, 2006).

Por último, los estudios de género desde los EO buscan entender los vínculos entre contexto organizacional, género y trabajo (ACKER, 2006; CALAS; SMIRCICH, 1996). El género, es considerado como "la red de creencias, rasgos de personalidad, actitudes, sentimientos, valores, conductas y actividades producto de un largo proceso histórico de construcción social, de desigualdades y jerarquías entre varones y mujeres quienes se encuentran en relaciones de poder asimétricas" (VÁZQUEZ; URBIOLA; 2014, p. 164). Desde esta corriente se hacen visibles los mecanismos a través de los cuales se reproduce la desigualdad y discriminación de género en las organizaciones, así como las formas simbólicas mediante las cuales se institucionalizan las diferencias entre hombres y mujeres. 


\section{LA UNIVERSIDAD COMO OBJETO DE ESTUDIO DE LOS EO}

Concebir a la universidad como objeto de estudio de los EO, radica en entenderla como una organización (DE LA ROSA; CONTRERAS, 2007); es decir, como una colectividad con unos límites relativamente identificables, que tiene un sistema normativo, un diseño estructural, un sistema de comunicación y objetivos comunes que responden a los intereses de los miembros de la organización, pero también de la sociedad (HALL, 1996). En este sentido, la universidad es una colectividad integrada por alumnos, docentes, personal administrativo y autoridades educativas que forman parte del universitas, donde los límites se determinan por el sistema de pertinencia, sean, por ejemplo, para los alumnos los exámenes de admisión y, para los docentes, los concursos de oposición. Por otro lado, la autonomía permite que las universidades establezcan en primer lugar, el sistema de reglas que guía su actuación. En segundo, les otorga independencia para construir el diseño estructural que auspicie la delegación de funciones y los niveles de responsabilidad bajo un esquema democrático. En tercer lugar, tienen libertad para instaurar las líneas de comunicación necesarias entre la comunidad.

En cuanto a los objetivos que la universidad como organización manifiesta, considérese que están relacionados estructuralmente con las funciones sustantivas que recaen en la docencia, investigación y extensión, cuyo impacto trasciende a la organización misma y sus actores; como pilar de la sociedad, es un sistema abierto en un medio de relaciones sociales, políticas, económicas, donde se involucran empresas, sociedad civil, padres de familia, Estado, entre otros. Un eje de su función social es brindar servicio a la sociedad, como consecuencia de la aceptación de las necesidades sociales que requieren del conocimiento que las universidades generan (VILLASEÑOR, 2003).

Aunado a ello, definir a las universidades como organizaciones también implica asimilarlas como espacios difusos donde sus integrantes emprenden procesos ambiguos y en ciertas condiciones de incertidumbre, ya que, a pesar de que dichos procesos se basan en la acción organizada de los individuos, ésta se limita por los marcos institucionales establecidos tanto al interior como al exterior de las organizaciones. Además de aquellos marcos, la acción 
organizada también se encuentra influenciada por lógicas de acción como la sentimental, la psicológica, la política o la cultura, entre otras (DE LA ROSA, 2002). Concebir a la universidad como organización, permite "hacer equivalentes y comparables realidades distintas, al reducirlas al comportamiento de ciertas variables estructurales en relación con distintos factores de su medio ambiente" (IBARRA, 2006, p. 128). Tales aseveraciones sobre el concepto de organización permiten analizar y entender a las universidades en su ámbito organizacional (MONTAÑO EN GUTIÉRREZ; VELÁZQUEZ; MARTÍNEZ; NAVA, 2014).

\section{EL ÁMBITO ORGANIZACIONAL DE LA UNIVERSIDAD.}

La concepción de la organización como un espacio ambiguo donde intervienen diversas lógicas de acción (DE LA ROSA, 2004), permite referir el ámbito organizacional de la universidad. Montaño (en GUTIÉRREZ et. al., 2014) asegura que este ámbito implica escudriñar la vida real de las universidades, donde se puede apreciar la compleja relación entre sus problemas, intereses, actores y contexto y la manera en que adquieren formas particulares, complejas y ambiguas. Esta visión discrepa del miramiento racionalista de la universidad y permite avanzar hacia una construcción integral y crítica de este tipo de organizaciones.

El ámbito organizacional de las universidades permite visualizarlas no sólo como entidades racionales orientadas a los fines enmarcados por sus funciones sustantivas, sino también como organizaciones complejas y ambiguas. La complejidad puede observarse en la relación entre los múltiples elementos que hay dentro y en torno a la universidad. A partir de dicha interrelación, este tipo de organizaciones tienen como fin ulterior sobrevivir en un ambiente dinámico, lo cual es complejo ya que se encuentran en la disyuntiva de alcanzar objetivos de eficiencia mediante parámetros instrumentales y cuantitativos, o seguir metas que obedezcan a la transformación social como parte de sus funciones sustantivas (BARBA; LOBATO, 2012).

En este mismo también se encuentra la ambigüedad reflejada en la indefinición de sus objetivos, reglas, decisiones y tomadores de decisiones (MIR, 2001). Dichos elementos no siempre siguen la racionalidad instrumental del costo-beneficio (MIRANDA, 2001), pues se 
ven presionados por diferentes factores internos como los recursos materiales, temporales, económicos y humanos con los que cuenta la universidad; y por factores externos como las demandas sociales, económicas y políticas. Ante ello, Solís (2001) argumenta que. las universidades se encuentran en la disyuntiva de tener que ser eficientes, pero también socialmente aceptadas y legitimadas, generando contradicciones e inconsistencias que los modelos racionales de toma de decisiones no explican.

Desde este ámbito, los EO han estudiado a la universidad como una anarquía organizada, donde se establece una relaciones complejas, caóticas y confusas entre los medios y los fines (MONTAÑO, 2012). Esta concepción de la universidad es útil para comprenderla no sólo desde una visión funcionalista, sino desde su versatilidad y flexibilidad; rescatando los diferentes aspectos, problemas y coyunturas propios de cada universidad y de las "maneras propias de asumir sus funciones principales" (MONTAÑO, 2012: 54).

Desde aquella concepción puede comprenderse cómo la universidad puede cambiar, desacoplarse, reajustarse y moverse en múltiples direcciones; lo cual es una capacidad que le permite convivir con el desorden, la contradicción y la incertidumbre (MIR, 2001). Las universidades, afirma Weick (1976), pueden autorregularse por la flexibilidad de sus procesos y elementos a pesar del caos y el desequilibrio que viven cotidianamente. Esto les permite improvisar decisiones y acciones con las cuales pueden responder a las contingencias o a los períodos de incertidumbre.

\section{APORTES DE LOS ESTUDIOS ORGANIZACIONALES PARA EL ESTUDIO DE LA UNIVERSIDAD LATINOAMERICANA}

En América Latina resalta la necesidad de construir una agenda de investigación en los diferentes países de la región. En sus inicios, el conocimiento organizacional se centró en las vertientes clásicas de la administración, atendiendo las demandas del sector empresarial (SZLECHTER et al., 2020). Como señala Ibarra (2006), la tendencia en Latinoamérica, al menos hasta la década de los ochenta, se centró en analizar las relaciones de dependencia y subordinación de la región frente a las economías dominantes, trayendo consigo una agenda 
de investigación focalizada en las dificultades estructurales del desarrollo económico, el atraso y la pobreza y el predominio de regímenes de gobierno autoritarios.

La apertura económica, el neoliberalismo como método de racionalización en las acciones de gobierno y la incidencia mercantil en distintas esferas, modificó el escenario, “propiciando el análisis sistemático de los problemas específicos de la organización, gobierno y desempeño que ocuparán paulatinamente un lugar más relevante en las agendas de investigación de las disciplinas sociales" (IBARRA, 2006, p. 127). Es entonces cuanto se considera indispensable abordar los problemas de las organizaciones desde las realidades locales, avanzando en una perspectiva crítica que adhiera la lógica histórica de las comunidades en América Latina, sus valores y modos de racionalidad (IBARRA, 2006).

Paulatinamente los EO fueron ganando terreno, concentrando estudiosos que se han adherido al campo para discutir sobre propuestas teóricas y metodológicas en un esfuerzo por encontrar aproximaciones críticas de análisis a la realidad organizacional. En Brasil, los EO datan de la década de los cincuenta y actualmente tienen dos líneas de pensamiento, una ligada a la administración y la otra a las ciencias humanas y sociales. También destaca la corriente crítica que tiene tres aristas. La primera aborda temas como la explotación del trabajo, las relaciones entre Estado y clases sociales y la crítica a la economía política del poder por mencionar algunas. La segunda se centra en los Critical Management Estudies y la tercera el análisis crítico en los EO que se focalizan en aspectos diversos aspectos simbólicos (MIRANDA-GONZALES; RAMÍREZ, 2017).

En México, los EO inician en 1995 con el Programa de Posgrado en EO (PPEO) en la Universidad Autónoma Metropolitana (UAM) que rápidamente se diseminó entre reconocidas universidades públicas del país a partir de convenios de colaboración con una postura meramente crítica, orientada a comprender de la realidad organizacional. En Colombia, programas de posgrado como la Maestría en Ciencias de la Organización en la Universidad del Valle de Cali (1997), la maestría en Ciencias de la Administración (1995) y el Doctorado en Administración en la Universidad EAFIT (2005) han abierto un espacio para mirar críticamente desde las ciencias sociales las prácticas administrativas en las organizaciones. 
Dado lo anterior, se puede afirmar que, en la actualidad, el campo de los EO América Latina se encuentra en un proceso de constitución y desarrollo de identidad, caracterizándose por ser heterogéneo, fragmentado y diverso (MIRANDA-GONZALES, 2020; MIRANDA-GONZALES; RAMÍREZ, 2017; RAMÍREZ; MIRANDA, 2019)

Ahora bien, las universidades son un tema recurrente en la producción académica del campo en América Latina. Existen algunos trabajos que han avanzado en la construcción de un mapa que de cuenta del estado actual de la investigación en un contexto local. Por ejemplo, el trabajo de Muñoz (2018) examina las características y frecuencia de las investigaciones publicadas en la Revista Venezolana de Gerencia durante 2008-2017 donde figura la universidad como objeto de estudio de los EO. Entre los resultados se enuncia que los principales temas de interés son relativos a la forma de organización, en segundo lugar, figuran las investigaciones dirigidas a los actores universitarios y grupos de interés y, en tercer lugar, lo referido a la formación, investigación y vinculación social. Se suma el análisis que realizan Ramos y Cadena (2018) respecto de las tesis del PPEO de la UAM Iztapalapa para identificar las principales estrategias metodológicas utilizadas, concluyendo que las investigaciones son principalmente de corte cualitativo y optan por el estudio de caso como método para el diseño de la investigación. De igual manera, se resalta que los tópicos de los EO más referidos en las investigaciones son el nuevo institucionalismo, cambio y cultura organizacionales.

En suma, para estudiar a la universidad latinoamericana, los aportes y corrientes teóricas de los EO ofrecen concepciones y herramientas analíticas que resultan útiles para un estudio crítico e integral, que recupera sus especificidades y desarrollo histórico de una visión crítica, comprensiva y local. Dichos aportes sirven, específicamente, para analizar el nivel organizacional de la universidad, es decir, los elementos que inciden en sus realidades y cotidianidades (MONTAÑO en GUTIÉRREZ et. al., 2014). Este análisis contribuye a establecer las bases de una agenda en la que se pueda avanzar en mapear las investigaciones que involucren a la universidad como objeto de estudio bajo la mirada de las corrientes de los EO en América Latina, a partir, por ejemplo, de la producción académica. En este sentido, 
exponemos algunos acercamientos conceptuales que sirven para trazar las interrelaciones analíticas, que no son mutuamente excluyentes, concentradas en la Tabla 1.

Tabla 1: Aportes de los Estudios Organizacionales para el estudio de la universidad

\section{latinoamericana}

\begin{tabular}{|c|c|c|}
\hline Corriente & Supuestos & Interrelación analítica \\
\hline Poder & $\begin{array}{l}\text { Poder como conjunto de relaciones } \\
\text { complejas limitadas por las estructuras } \\
\text { de la organización (CROZIER, 1973). }\end{array}$ & $\begin{array}{l}\text { - } \text { Conflictos } \\
\text { - Relaciones de Poder } \\
\text { - Dinámicas y conflictos } \\
\text { relacionados con su estructura de } \\
\text { gobierno } \\
\text { - Gobernabilidad y gobernanza }\end{array}$ \\
\hline $\begin{array}{l}\text { Análisis } \\
\text { estratégico }\end{array}$ & $\begin{array}{l}\text { Acción de los integrantes de una } \\
\text { organización y a su capacidad } \\
\text { estratégica para modificar las } \\
\text { estructuras a través de determinados } \\
\text { juegos de poder que funcionan como } \\
\text { mecanismos de regulación (CROZIER; } \\
\text { FRIEDBERG, 1990). }\end{array}$ & $\begin{array}{l}\text { - Juegos de conflicto y cooperación } \\
\text { - Sistema de acción concreto } \\
\text { - Redes } \\
\text { - Evaluación del desempeño } \\
\text { - Financiamiento de la ES }\end{array}$ \\
\hline Redes & $\begin{array}{l}\text { Análisis de las organizaciones a nivel } \\
\text { macrosocial, específicamente en cuanto } \\
\text { a las relaciones que aquellas tienen con } \\
\text { el medio ambiente (BARBA, 2013). }\end{array}$ & $\begin{array}{l}\text { Economía capitalista del } \\
\text { conocimiento } \\
\text { - Evaluación del desempeño } \\
\text { académico } \\
\text { - Gobernabilidad y gobernanza }\end{array}$ \\
\hline $\begin{array}{l}\text { Ambigüedad y } \\
\text { anarquías } \\
\text { organizadas }\end{array}$ & $\begin{array}{l}\text { Falta de claridad o de consistencia en la } \\
\text { realidad, causalidad o intencionalidad } \\
\text { (MARCH, 1994). }\end{array}$ & $\begin{array}{ll}\text { - } & \text { Gestión universitaria } \\
\text { - } & \text { Mercantilización educativa } \\
\text { - } & \text { Calidad }\end{array}$ \\
\hline $\begin{array}{l}\text { Ecología } \\
\text { organizacional }\end{array}$ & $\begin{array}{l}\text { Las organizaciones sobreviven debido } \\
\text { al ambiente en el que se encuentran } \\
\text { (BARBA; SOLIIS, 1997). }\end{array}$ & $\begin{array}{l}\text { - Supervivencia } \\
\text { - Continuidad, fracaso, } \\
\text { adaptabilidad o desaparición }\end{array}$ \\
\hline $\begin{array}{l}\text { Nuevo } \\
\text { institucionalismo }\end{array}$ & $\begin{array}{l}\text { A nivel macro, se concibe a la } \\
\text { estructura organizacional como } \\
\text { resultado de una serie de mitos } \\
\text { racionalizados. En el nivel micro, se } \\
\text { encuentran los procesos de } \\
\text { institucionalización sucedidos en las } \\
\text { relaciones interpersonales dentro de } \\
\text { un contexto sociocultural (DE LA ROSA, } \\
2002 \text { ). }\end{array}$ & $\begin{array}{ll}\text { - } & \text { Campos organizacionales } \\
\text { - } & \text { Mitos racionalizados } \\
\text { - } & \text { Isomorfismo } \\
\text { - } & \text { Megitimidad institucional } \\
\end{array}$ \\
\hline Antropología de & $\begin{array}{l}\text { El individuo, es concebido como un ser } \\
\text { humano complejo que establece }\end{array}$ & $\begin{array}{l}\text { - Símbolos y significados de las } \\
\text { universidades }\end{array}$ \\
\hline
\end{tabular}




\begin{tabular}{|c|c|c|}
\hline las organizaciones & $\begin{array}{l}\text { relaciones de diversa índole con su } \\
\text { medio ambiente y con las } \\
\text { organizaciones a las cuales pertenece } \\
\text { (CHANLAT, 1998; CHANLAT; BÉDARD, } \\
\text { 2000). }\end{array}$ & $\begin{array}{l}\text { - Pertinencia de la educación } \\
\text { superior }\end{array}$ \\
\hline $\begin{array}{l}\text { Organización } \\
\text { postmoderna/ } \\
\text { Análisis } \\
\text { postmoderno de } \\
\text { las organizaciones }\end{array}$ & $\begin{array}{l}\text { Organizaciones flexibles, cuyas } \\
\text { principios se sustentan en las } \\
\text { tecnologías de nueva generación } \\
\text { (HEYDEBRAND, 1989). }\end{array}$ & $\begin{array}{ll}\text { - } & \text { Transformación de las } \\
\text { universidades para responder al } \\
\text { contexto } \\
\text { - } \\
\text { Mercantilización educativa }\end{array}$ \\
\hline $\begin{array}{l}\text { Psicoanálisis en las } \\
\text { organizaciones }\end{array}$ & $\begin{array}{l}\text { La relación organización- individuo se } \\
\text { basa en las estructuras establecidas en } \\
\text { el inconsciente de los individuos } \\
\text { (AUBERT; DE GAULEJAC, 1993). }\end{array}$ & $\begin{array}{ll}\text { - } & \text { Contradicciones en el entorno } \\
\text { Social } \\
\text { - Significado social de la } \\
\text { universidad }\end{array}$ \\
\hline Cultura & $\begin{array}{l}\text { La cultura en las organizaciones } \\
\text { identifica los elementos simbólicos que } \\
\text { dan sentido a una organización } \\
\text { (SMIRCICH, 1983). }\end{array}$ & $\begin{array}{l}\text { - } \quad \text { Prácticas y costumbres } \\
\text { - } \quad \text { Aspectos simbólicos } \\
\text { - } \quad \text { Identidad } \\
\text { - } \quad \text { Sistemas de significados }\end{array}$ \\
\hline $\begin{array}{l}\text { Aprendizaje y } \\
\text { conocimiento } \\
\text { organizacional }\end{array}$ & $\begin{array}{l}\text { Capacidad de las organizaciones para } \\
\text { emprender nuevos procesos de } \\
\text { aprendizaje y crear conocimientos } \\
\text { propios, o adoptar conocimientos de } \\
\text { otras organizaciones (ARGYRIS; } \\
\text { SCHÖN, 1978) }\end{array}$ & $\begin{array}{l}\text { Vinculación entre universidad y } \\
\text { sociedad } \\
\text { Evaluación del desempeño } \\
\text { académico }\end{array}$ \\
\hline $\begin{array}{l}\text { Cambio } \\
\text { organizacional }\end{array}$ & $\begin{array}{l}\text { Procesos de transformación por los } \\
\text { cuales atraviesan las organizaciones } \\
\text { (VAN DE VEN; POOLE, 1995) }\end{array}$ & $\begin{array}{ll}\text { - } & \text { Calidad educativa } \\
\text { - } & \text { Programas de fortalecimiento } \\
\text { institucional } \\
\text { - } \\
\text { Pertinencia de la educación } \\
\text { superior } \\
\text { - } & \text { Autonomía } \\
\end{array}$ \\
\hline Estudios de género & $\begin{array}{l}\text { Vínculos entre contexto organizacional, } \\
\text { género y trabajo (ACKER, 2006; CALAS; } \\
\text { SMIRCICH, 1996) }\end{array}$ & $\begin{array}{l}\text { - } \quad \text { Desigualdad y violencia de género } \\
\text { - } \quad \text { Equidad de la educación superior }\end{array}$ \\
\hline
\end{tabular}

Fuente: Elaboración propia con base en: Acker (2006), Argyris y Schön (1978), Aubert y de Gaulejac (1993) Barba (2013), Barba y Solís (1997), Calas y Smircich (1996), Crozier (1973), Crozier y Friedberg (1990), De la Rosa (2002), Heydebrand (1989), March (1994), Smircich (1983), Van de Ven y Poole (1995).

Por ejemplo, el estudio del poder en las organizaciones es de utilidad para explicar algunas de las problemáticas de las universidades latinoamericanas como los conflictos y tensiones; el estudio del poder permite analizar el papel de las relaciones de poder en la generación de conflictos, desconfianza y altos costos de transacción ante los constantes 
cambios a los cuales se ven sometidas las universidades, tales como las dinámicas y conflictos relacionados con su estructura de gobierno (KENT; ÁLVAREZ; GONZÁLEZ; RAMÍREZ; DE VRIES, 2003).

El estudio del poder también aporta a la comprensión de las tensiones con autoridades externas, ya que hace posible visibilizar cómo el conflicto interior de las universidades puede escalar hacia niveles externos, involucrando a las autoridades y organizaciones ajenas a los objetivos pedagógicos de la universidad (MIRANDA, 2001). En al ámbito de la gestión de las universidades, esta corriente permite ver cómo la centralización en la toma de decisiones en las universidades desemboca en el establecimiento de relaciones de poder que contradicen los objetivos establecidos por la universidad (ARECHAVALA, SOLÍS, 1999).

Asimismo, los aportes teóricos del análisis estratégico pueden contribuir al análisis de la diversidad de intereses que se involucran en la universidad, y para explicar cómo sus actores entran en un juego de conflicto y cooperación (GUERRERO, 2010). Especialmente, para la universidad latinoamericana, este enfoque permite analizar cómo ésta se conforma como un sistema de acción concreto, en el cual se establece determinada lógica definida por la red de relaciones establecidas entre gobiernos locales, autoridades universitarias, académicos y administrativos (GUERRERO, 2010), lo que pudiera contribuir a analizar cómo construir redes alternas para la obtención de recursos. La problemática de la evaluación del desempeño académico también puede estudiarse a la luz del análisis estratégico, ya que los mecanismos de evaluación pueden ser entendidos como mecanismos de regulación que establecen la lógica de la educación superior o de la investigación (DE LA ROSA; LÓPEZ; PÉREZ, 2004).

Una de las temáticas que puede ser analizada con el enfoque de redes es la economía capitalista del conocimiento que define la pertinencia de las universidades, entendida como un elemento que influye en la implementación de políticas públicas neoliberales diseñadas por gobiernos en red que se aplican por igual a universidades situadas en países con diferentes características y necesidades (DE MENDONCA, 2011). Otra cuestión que puede ser retomada desde el mismo enfoque es la evaluación del desempeño, si se toma como punto de 
partida el establecimiento de redes entre universidades y organismos de educación internacionales que definen nuevos mecanismos de valoración y homogeneización (MONTAÑO, 2001).

Por su parte, los postulados de la ambigüedad y de las anarquías organizadas son idóneos para explicar y analizar la problemática de la gestión universitaria, ya que ayuda a entender por qué las universidades de Latinoamérica intentan cumplir objetivos de diversa índole; lo cual las lleva a no tener objetivos precisos ni formas de gestión planificadas para conseguirlos (MIRANDA, 2001). Las universidades se conforman como organizaciones desordenadas, ambiguas y abstractas donde prevalece el desorden y la contradicción (MIR, 2001). Asimismo, estos aportes teóricos podrían ser útiles para explicar las implicaciones que para las universidades de Latinoamérica tiene el seguir la lógica empresarial y cómo ha sido la adaptación de aquellas a dicha lógica (MONTAÑO, 2012). También el tema de la calidad se puede incluir en esta categoría, siendo que la imprecisión del término da lugar a que se analice cómo las universidades lo adaptan a sus estructuras.

La ecología organizacional resulta pertinente para analizar las características específicas de las universidades latinoamericanas y la injerencia de aquellas en su supervivencia o desaparición. Sirven, también, para analizar el paso evolutivo de estas universidades e identificar hacia dónde se dirigen, es decir, su continuidad, fracaso, adaptabilidad o desaparición. Ejemplo de ello, son las universidades privadas, cuya heterogeneidad y contexto, han hecho del prestigio un elemento imprescindible para su supervivencia (MORALES, 2013).

Los aportes del nuevo institucionalismo se han utilizado de manera extensa en los EO para investigar el campo de la educación superior, ya que permiten analizar cómo las universidades conforman ciertos campos organizacionales con características específicas, como es el caso de las universidades privadas en México (BUENDÍA, 2014). Asimismo, hace posible la identificación y explicación de los mitos racionalizados que se arraigan en la educación superior, tales como los criterios estandarizados de la evaluación del desempeño (BUENDÍA, 2010); los cuales tienen tal arraigo que terminan por convertirse en procesos 
institucionalizados que dan forma a la evaluación y acreditación de la educación superior (BUENDÍA, 2014). También se pueden vincular aquí temáticas como el análisis de la legitimidad institucional y la mercantilización educativa, si se considera que las universidades se desarrollan en un campo organizacional donde ocurren procesos de isomorfismo.

La antropología de las organizaciones es oportuna para estudiar la interacción de los símbolos y significados que influyen en las universidades. Al centrarse en elementos inherentes al ser humano, los aportes de esta corriente pueden auxiliar en la comprensión de cuestiones como la creación del conocimiento, la libertad académica, la pretensión de verdad, la enseñanza del libre pensamiento, el interés por una educación liberadora, valores que prevalecen en la comunidad y que inciden en la universidad, así como las relaciones que ésta establece con la sociedad (RAMÍREZ; BÉDARD, 2012). En este entendido, la antropología de las organizaciones resulta interesante para analizar, por ejemplo, la pertinencia de la educación superior, no sólo desde una postura orientada al mercado laboral, sino acorde con las estructuras de significados atribuidos a las universidades en un contexto local.

La concepción teórica de la organización postmoderna puede aportar a la comprensión de la transformación constante de las universidades para responder a las demandas del contexto y a los lineamientos de las políticas públicas que se aplican en determinados contextos; lo cual provoca que la universidad adopte diversas formas de organización, con base en determinadas particularidades contextuales y organizacionales (BARBA; LOBATO, 2012). Asimismo, aportaría al estudio de la economía capitalista del conocimiento a la que actualmente se están adaptando las universidades, con la aparición de mercados de servicios educativos que provocan la consolidación de nuevos tipos de universidades; por ejemplo, las de educación a distancia o las privadas de absorción de demanda (DE LEÓN, 2015).

El análisis postmoderno de las organizaciones puede ser apto para analizar la reapropiación de ciertos discursos en las universidades y la incorporación de prácticas discursivas del contexto social hacia el interior de la universidad. Así, estos aportes pueden ayudar a estudiar cómo se concibe a la universidad a partir de ciertos discursos y cómo sus 
elementos se cimentan en determinadas narrativas incorporadas por sus integrantes, tales como los deseos, las emociones, las creencias o los significados (PÉREZ, 2013). Asimismo, esta corriente ayuda a comprender la incidencia de las narrativas locales y globales en las universidades, tal como ha sucedido con el discurso de la calidad (BARBA, 2012) y las implicaciones de la mercantilización educativa.

El psicoanálisis en las organizaciones es pertinente para analizar a las universidades como instituciones que reflejan las contradicciones que se viven en el entorno social, como la lucha por la libertad y el sometimiento a diversas formas de esclavitud (FERNÁNDEZ, 1994). Desde este punto de vista, la universidad puede ser analizada en cuanto a sus acciones y el significado social de ellas.

El estudio de la cultura en las organizaciones puede aportar a las universidades para el análisis de las prácticas y costumbres de sus diferentes actores y como, a partir de éstas, se establece un sistema de significados y referentes que dan forma a la identidad de la universidad latinoamericana; tal como ocurre con las universidades interculturales que basan su identidad en ciertos referentes proveniente de la historia de sus contextos (HIDALGO, 2015).

Por otro lado, el aprendizaje y conocimiento organizacional coadyuva en el análisis de las universidades como organizaciones creadoras de nuevo conocimiento, y como organizaciones que integran los conocimientos de sus académicos. Desde este punto de vista, puede aportar en el análisis crítico de los mecanismos de evaluación del desempeño académico. También contribuye al estudio de la vinculación entre universidad y sociedad, a partir de los conocimientos que ambas generan (MORALES, 2007).

La corriente de cambio organizacional ayuda al análisis de las transformaciones que ha experimentado la universidad. Ejemplo de ello es la concepción de calidad educativa que prevalece en el nivel superior, la cual se basa en estándares de origen empresarial que rigen la economía capitalista del conocimiento que predomina en esta era neoliberal (BARBA, 2012). Los aportes teóricos en el tema de la cultura organizacional también pueden ser de 
utilidad para analizar los procesos planeados de cambio que se implementan en las universidades, por ejemplo, a través de la formulación y puesta en marcha de programas de fortalecimiento institucional. Se puede trazar también un panorama que permita evaluar cómo se ha transformado el concepto de autonomía universitaria. Incluso, es útil para develar cómo se ha transformado la pertinencia desde un punto de vista histórico en la región.

Por último, desde los estudios de género, se puede hacer visible la desigualdad de género que se manifiesta en las universidades, las cuáles han sido espacios históricamente desfavorables para las mujeres, quienes durante siglos no tuvieron el acceso a la educación superior. Si bien, es progresiva su presencia, las desigualdades, la violencia de género, las situaciones de acoso y hostigamiento persisten en la comunidad en todos los niveles (ORDORIKA, 2015), por lo cual esta corriente aporta la comprensión del fenómeno y tiene aplicaciones útiles, como la búsqueda de equidad en el acceso a la educación superior y en propuestas que busquen erradicar tales situaciones.

\section{CONCLUSIONES}

Las universidades latinoamericanas enfrentan situaciones de índole político, económico, ético, pedagógico y educativo las cuales responden al desarrollo contextual específico de cada forma organizacional (JARA HOLLIDAY, 2018). En este trabajo se ofrece una perspectiva de la universidad latinoamericana a través de su historia y la identificación de algunos puntos en común que caracterizan a las organizaciones de educación superior en la región. Lo anterior ha permitido argumentar que los EO son un campo de estudio pertinente para un estudio crítico e integral de estas. La pertinencia de este campo radica en que se integra por diversos aportes y corrientes teóricas que resultan útiles para comprender los múltiples fenómenos de distintos tipos de organizaciones (CONTRERAS; DE LA ROSA, 2013), entre ellas, las universidades.

Concebir a la universidad como objeto de estudio de los EO permite analizarla en su nivel organizacional. En otras palabras, como una organización que adquiere formas particulares, conformadas a partir de ciertos elementos internos y factores contextuales. 
Aunque, también permite considerar su nivel institucional, es decir, las características de su tipo ideal como organización educativa, el cual la insta a compartir características, objetivos y problemáticas con otras organizaciones educativas (MONTAÑO en GUTIÉRREZ et. al., 2014).

Ante ello, se considera que los aportes teóricos de los EO permiten analizar, desde una perspectiva organizacional, los elementos que hacen de la universidad latinoamericana una forma de organización particular, reconociendo su historicidad y su papel en la transformación de las realidades económicas, políticas y sociales de la región (RHOADES, et al., 2004). Al mismo tiempo que permiten identificar elementos que hacen de ella una organización que forma parte de un determinado sistema educativo, donde hay otras universidades que comparten sus ideales, expectativas y demandas.

Una de las limitaciones de este trabajo consiste en que ha sido un ejercicio bastante general que debe profundizarse al menos en tres sentidos: primero, integrando otras problemáticas que enfrentan las universidades latinoamericanas y elementos que influyen en sus conformaciones específicas dependiendo de su contexto y desarrollo histórico. Es importante la identificación de aquellos pues contribuyen a su comprensión desde la complejidad de sus realidades.

Por otra parte, resultaría conveniente agregar otros aportes teóricos de los EO, los cuales posibiliten un estudio más preciso de las vicisitudes de la universidad latinoamericana como una forma de organización particular. Asimismo, resulta conveniente integrar al estudio las nuevas corrientes que han empezado a ser consideradas dentro del campo de los EO, por ejemplo, colonialismo, innovación, empresarismo, entre otros (GONZALES-MIRANDA, 2020). Los aportes de éstas bien pueden contribuir a un estudio organizacional crítico y alternativo de las universidades de Latinoamérica.

Una tercera tarea desprendida de este trabajo es construir puentes teóricos y metodológicos para generar propuestas que resulten integradoras en el estudio organizacional de las universidades latinoamericanas. La tradición metodológica del campo de los EO posee un énfasis interpretativista donde prepondera el papel del lenguaje, los 
significados, el contexto y la interacción con los actores para construir conocimiento sobre las organizaciones; por lo que destacan los métodos cualitativos de investigación como el estudio de caso, el análisis conversacional, el análisis del discurso y la etnografía (SANABRIA; SAAVEDRA; SMIDA, 2013). Las corrientes aquí expuestas pueden enriquecerse al vincularlas con estos referentes metodológicos.

Si bien este ejercicio presenta limitaciones, también tiene importantes aportaciones. La primera es que ha permitido ilustrar cómo, desde el campo de los E0, el tema de la universidad latinoamericana y sus problemáticas pueden ser abordados desde diferentes enfoques. Esto cual permite indagar y comprender la complejidad de las universidades desde diversos ejes de análisis de una manera crítica, ya que los EO representan un marco teóricometodológico alternativo al análisis actual del campo de la educación superior.

Ante ello, se considera que este estudio puede ser útil para quienes se acercan por primera vez al estudio organizacional de las universidades, ya que muestra un panorama de cómo algunas de sus problemáticas pueden ser abordadas desde los EO. No obstante, por las limitaciones de este ejercicio y la pertinencia de llevarlo más a profundidad, también se considera relevante conformar una agenda de investigación, donde se propongan estudios potenciales de las universidades latinoamericanas a partir de los aportes y corrientes teóricas de los EO y un análisis a preciso sobre la literatura académica producida en el campo.

\section{REFERENCIAS}

ACKER, J. Gender and Organizations. En J. Saltzman C. (coord.) Handbook of the Sociology of Gender, (177-194). Huston, Texas: Springer, 2006.

ACOSTA, S.A. 100 años después. Autonomía y poder universitario en América Latina. Revista Latinoamericana de Educación Comparada, 9(13), 2018, 72-92.

ACOSTA, S.A. El neointervencionismo estatal en la educación superior en América Latina, Sociológica, 17(48), 2002, 43-72.

ACOSTA, S.A. El poder de la universidad en América Latina: historia, sociología y política en la época colonial (1538-1812). Texto presentado en el Seminario de investigación 20162017 organizado por FLACSO- España, el Instituto Iberoamericano y el Área de Ciencia Política de la Universidad de Salamanca, 2016. 
ACOSTA, S.A.; ATAIRO, D.; CAMOU, A. Gobernabilidad y democracia en la universidad pública latinoamericana: Argentina y México en Perspectiva Comparada. En A. SILVA et. al. Los desafíos de la universidad pública en América Latina y el Caribe CLACSO, 2015, 9-118.

ARECHAVALA, R.; SOLÍS, P. (coord.) La Universidad pública. ¿Tiene rumbo su desarrollo en México? México: Eds. Universidad de Guadalajara y Universidad Autónoma de Aguascalientes, 1999.

ARGYRIS, C.; SCHÖN, D. A. Organizational learning: A theory of action perspective. Massachusetts, Addison-Wesley, 1978.

AUBERT, N.; DE GAULEJAC, V. El coste de la excelencia. Barcelona: Paidós, 1993.

BARBA, A. Administración, teoría de la organización y estudios organizacionales. Tres campos de conocimiento, tres identidades. Gestión y estrategia, 21 (44), 2013, 139-152.

BARBA, A. La calidad de las instituciones de educación superior en México. ¿De lo privado a lo público? En BARBA A. Y LOBATO C. (coord.) Instituciones de Educación Superior Políticas Públicas y Organización, México: Porrúa, 2012, 135-150.

BARBA, A.; LOBATO, O. Las Instituciones de Educación Superior desde la perspectiva del análisis organizacional. En BARBA A.A; LOBATO O.C. (coord.), Instituciones de Educación Superior Políticas Públicas y Organización. México: Porrúa, 2012, 5-14.

BARBA, A.; SOLÍS, P. Cultura en las organizaciones Enfoques y Metáforas de los Estudios Organizacionales. México: Vertiente Editorial, 1997.

BUENDÍA, M. A. Análisis institucional y educación superior. Aportes teóricos y resultados empíricos. Perfiles Educativos, 33 (124), 2010, 8-33.

BUENDÍA, M. A. La FIMPES y la mejora de la calidad en instituciones privadas Cambio, prestigio y legitimidad. Tres estudios de caso (1994-2004). México: ANUIES, 2014.

CALAS, M. B.; SMIRCICH, L. From 'the woman's point of view: feminist approaches to organization studies. En S. CLEGG, C. HARDY; W. NORD (eds.), Handbook of organization studies (218-257). Londres: Sage 1996.

CHANLAT, A.; BÉDARD, R. La gestion, une affaire de parole. EN CHANLAT, J. L'individu dans l'organisation. Les dimensions oubliées Montréal: Les presses de l'Université Laval y Editions Eska, 2000, 79-99.

CHANLAT, J. Sciences socials et management. Plaidoyer pour une anthropologie générale. Montréal: Les presses de l’Université Laval y Editions Eska, 1998.

CHREIM, S. Managerial Frames and Institutional Discourses of Change: Employee Appropriation and Resistance. Organization Studies, 9(27), 2006, 1261-1287. 
CLEGG, S. Modern Organizations. Organization Studies in the postmodern world. London: Sage, 1990.

CLEGG, S.; HARDY, C. Introduction. Organizations, organization and organizing. EN CLEGG, S. R.; HARDY, C.; NORD, W. R. (coord.), Handbook of Organization Studies, London: Sage, 1996a, 1-28.

CLEGG, S.; HARDY, C. Some dare calls it power. EN CLEGG, S. R.; HARDY, C.; NORD, W. R. (coord.), Handbook of Organization Studies, London: Sage, 1996b, 622-641.

COHEN, M.; MARCH, J. Leadership and ambiguity. United States, Harvard Business School Press, 1974.

COHEN, M., MARCH, J.; OLSEN, J. A garbage can model of organizational choice. Administrative Science Quarterly, 17(1), 1972, 1-25.

CONTRERAS, J. C. M.; DE LA ROSA, A. A. Organizaciones y políticas públicas. Elementos para trabajar una perspectiva organizacional de las políticas públicas. En de LA ROSA, A. A.; CONTRERAS, J. C. M. (coord.), Hacia una perspectiva organizacional de la política pública. Recortes y orientaciones iniciales, México: Fontamara, 2013, 13-56.

CROZIER, M. The problem of power. The strategic society, 1973, 211-228.

CROZIER, M.; FRIEDBERG, E. El actor y el sistema. México: Alianza, 1990.

DE LA ROSA, A. Teoría de la Organización; Nuevo Institucionalismo en el Análisis Organizacional. Administración y Organizaciones, 4(8), 2002, 13-44.

DE LA ROSA, A.; LÓPEZ, A.; PÉREZ, M. Á. La acreditación mediante el Sistema Nacional de Investigadores como mecanismo de regulación de la investigación. Algunas reflexiones organizacionales a partir de un estudio de caso. Vetas, 6(19), 2004, 70-107.

DE LEÓN, S. La institucionalización de la educación a distancia. Caso de la Universidad Autónoma Metropolitana. (Tesis inédita de doctorado). México: UAM-I, 2015.

DE MENDONCA, V. L. Universidad y empresa. Los vínculos entre el conocimiento y la productividad. México: Fontamara, 2011.

DEAL, T.; KENNEDY, A. Culturas Corporativas, Ritos y rituales de la vida organizacional. Buenos Aires: Fondo Educativo Interamericano, 1985.

DÍAZ, B. Autonomía universitaria. Orígenes y futuro de la realidad mexicana. Revista de la Educación Superior, 33 (129), 2004, 41-48. 
DIDRIKSSON, T.A. El futuro anterior. La universidad como sistema de producción de conocimientos, aprendizajes e innovación social. En A. SILVA et. al. Los desafíos de la universidad pública en América Latina y el Caribe, CLACSO, 2015, 381-412.

DONOSO, R.A. Puntos de encuentro: movimientos estudiantiles en México y Brasil en 1968. UDUAL Universidades. (76), 2018.

ENRIQUEZ, E. La pasión por la psicosociología Entrevista con Eugene Enriquez. En MONTAÑO H.L. (coord.), Enigmas y Laberintos, México: Universidad Autónoma Metropolitana, 2007, 49-79.

FERNÁNDEZ, L. (1994). Instituciones educativas. Dinámicas institucionales en situaciones críticas. México: Paidós, 1994.

FERNÁNDEZ, L.N.; COPPOLA, N. Desafíos para la construcción del espacio latinoamericano de educación superior en el marco de las políticas supranacionales. Journal of Supranational Policies of Education, 1, 2013, 67-82.

GACEL-ÁVILA, J.; JARAMILLO, I. C.; KNIGHT, J.; DE WIT, H. The Latin American Way: Trends, Issues, and Directions. En DE WIT, H.; JARAMILLO, I. C.; GACEL-ÁVILA, J.; KNIGHT, J. (eds.) Higher Education in Latin America. The International Dimension. Washington, D.C.: The World Bank, 2005, 341-368.

GARCÍA-DE-LA-TORRE, C. Representaciones y reflexiones de la investigación sobre organizaciones en América Latina. En: RAMÍREZ, G.; GONZÁLEZ, D.M. (eds.) Tratado de Estudios Organizacionales: Volumen 1. Teorización del Campo. Colombia: EAFIT, 2017, 913-944.

GONZALES-MIRANDA D. M.; RAMÍREZ, G. Introducción: los estudios organizacionales en Latinoamérica. Una realidad fragmentada en busca de una identidad. En: Ramírez, G.; González, D.M. (eds.) Tratado de Estudios Organizacionales: Volumen 1. Teorización del Campo. Colombia: EAFIT, 2017, 23-40.

GONZALES-MIRANDA. Organizational Studies in Latin America: Back to The Rough Ground. RAE. 60(2), 2020, 104-119.

GREEN, S. (1988). Understanding corporate culture and its relation to strategy. Int. studies of management and organization, 18(2), 1988, 6-28.

\section{GUERRERO, P. La Construcción Del Sistema De Acción Concreto En La Universidad} Autónoma De La Ciudad De México. (Tesis inédita de doctorado). México: UAM-I, 2010.

GUTIÉRREZ, C.; VELÁZQUEZ, F. J.; MARTÍNEZ, J. A.; NAVA, N. (2014). Autonomía: La otra cara de la responsabilidad. [Entrevista a Luis Montaño Hirose]. En NAVA, N. (coord.), Autonomía universitaria. Diálogos, reflexiones y perspectiva, México: Universidad de Guanajuato, 2014, 193-213. 
HALL, R. Organizaciones, estructura y proceso. España: Editorial Prentice Hall, 1996.

HERNÁNDEZ, H.H.B.; MARTUSCELLI, Q.J.; MOCTEZUMA, N.D.; MUÑOZ. Los desafíos de las universidades de América Latina y el Caribe ¿Qué somos y a dónde vamos? Perfiles

Educativos, 32 (147), 2015, 202-2018.

HEYDEBRAND, W. New organizational forms. Work and occupations, 16 (3), 1989, 323-357.

HICKSON, H. Offence and Defense. Organization Studies, 9(1), 1988, 1-32.

HIDALGO, G. Construcción de la Identidad Organizacional en una Universidad Intercultural. Caso: Universidad Intercultural del Estado de Tabasco. (Tesis inédita de doctorado). México: UAM-I, 2015.

HOFSTEDE, G. Motivation, Leadership, and Organization: Do American Theories Apply Abroad. Organizational Dynamics, 6(1), 1980, 42-63.

HOLM-NIELSEN. L.B.; THORN, K.; BRUNNER, J. J.; BALÁN, J. Regional and International Challenges to Higher Education in Latin America. En DE WIT, H.; JARAMILLO, I. C.; GACELÁVILA, J.; KNIGHT, J. (eds.) Higher Education in Latin America. The International Dimension. Washington, D.C.: The World Bank, 2005, 341-368.

IBARRA, C. E. ¿Estudios Organizacionales en América Latina? Transitando del centro a las orillas. En De la Garza-Toledo (Ed.). Teorías Sociales y Estudios del Trabajo. Nuevos Enfoques, 88-107, México: Anthropos UAM, 2006.

IBARRA, C. E. La universidad en México hoy: gubernamentalidad y modernización, México: UNAM, 2001.

INEE-IIPE UNESCO La política educativa de México desde una perspectiva regional. México: Autores, 2018.

JARA HOLLIDAY, O. La educación popular latinoamericana. Historia y claves éticas, políticas y pedagógicas. San José: Alforja, 2018.

JIMÉNEZ, M.A. Educación y autonomía: hacia una sociología de las significaciones imaginarias de la educación, en JIMÉNEZ, M.A. (coord.), Encrucijadas de lo imaginario. Autonomía y práctica de la educación, México: Universidad Autónoma de la Ciudad de México, 2007, 169196.

KENT, R., G.; ÁLVAREZ, M.; GONZÁLEZ., R.; RAMÍREZ; W. DE VRIES. Cambio Organizacional y Disciplinario en las Ciencias Sociales en México. México: Plaza y Valdéz Editores, 2003.

LUCIANI, L. Movimientos estudiantiles latinoamericanos en los años sesenta. Historia y Memoria, 18, 2019, 77-111. 
MALAGÓN, P. L.A. La pertinencia en la educación superior: elementos para su comprensión. Revista de la Educación Superior, 32 (127), 2003, 113-134.

MARCH, J. A primer on Decisions Making. How Decisions Happens. 1994. Free Press.

MARCH, J. The Study of Organizations and Organizing Since 1945. Organization Studies, 28(1), 2007, 9-19.

MARCH, J.; OLSEN, J. Ambiguity and Choice in Organizations. Oslo: Universitetsforlaget, 1976.

MARSISKE, R. La autonomía universitaria. Un visión histórica y latinoamericana. Perfiles Educativos, 32, 2010, 9-26.

MIR, A. La Universidad moderna y los modelos organizacionales. EN BARBA, A.A.; MONTAÑO, H.L. (coords.), Universidad, organización y sociedad: arreglos y controversias. México: Porrúa, 2001, 99-103.

MIRANDA, F. Las universidades como organizaciones del conocimiento. El caso de la Universidad Pedagógica Nacional. México: El Colegio de México, Universidad Pedagógica Nacional, 2001.

MONTAÑO, L. La organización universitaria. Disputa y tensiones entre el modelo administrativo y la anarquía organizada. En BARBA, A. A.; LOBATO, O. C. (coord.), Instituciones de educación superior, políticas públicas y organización, México: UAM-I, Porrúa, 2012, 33-58.

MONTAÑO, L. Los nuevos desafíos de la docencia. Hacia la construcción -siempre inacabada de la universidad. En BARBA, A.A.; MONTAÑO, H.L. (coord.), Universidad, organización y sociedad: arreglos y controversias, México: Porrúa, 2001, 105-132.

MORALES, M. D. Construir la legitimidad Estrategias de una institución de educación superior privada. México: Biblioteca de la Educación Superior, 2013

MORALES, V. El conocimiento organizacional en la vinculación Universidad-sociedad: caso UAM-Iztapalapa. (Tesis inédita de doctorado). México: UAM-I, 2007.

MORENO, J.C.; RUÍZ, N. P. La educación superior y el desarrollo económico en América Latina. México: CEPAL, 2009.

MUÑOZ, R.M.D.C. Estudios organizacionales sobre la universidad, características y frecuencia en su investigación: Caso RVG. Sapienza Organizacional, 5(10), 2018, 1-22.

NONAKA, I.; TAKEUCHI, H. La organización creadora de conocimiento. Cómo las compañías japonesas crean la dinámica de la innovación. México: Oxford University Press, 1999. 
NOSIGLIA, M.C. La reforma universitaria de 1918 en debate: vigencia de sus principales postulados. Revista Latinoamericana de Educación Comparada, 9(13), 93-104.

ORDORIKA, I. Equidad de género en la Educación Superior. Revista de la Educación Superior. 44(174), 2015, 7-17.

ORDORIKA, I., LLOYD, M. Teorías críticas del Estado y la disputa por la educación superior en la era de la globalización. Perfiles Educativos, 36(145), 2014, 122-139.

PAGÈS, M., BONETTI, M., DE GAULEJAC, V.; DESCENDRE, D. L'emprise de l'organisation. Paris: Presses Universitaires de France, 1979.

PÉREZ, A. R. Discurso, representaciones sociales y narrativa en las organizaciones. El caso de tres cuerpos académicos de la Universidad Juárez Autónoma de Tabasco. (Tesis inédita de doctorado). México: UAM-I, 2013.

PÉREZ, M. Aseguramiento de la calidad de la educación superior en América Latina ¿Vamos por el camino correcto? Calidad en la Educación, (21), 2004, 271-285.

PIRES, S.; LEMAITRE, M.J. Sistemas de acreditación y evaluación de la educación superior en América Latina y el Caribe, 2008.

RAMA, C. La problemática del financiamiento de la educación superior en América Latina. Cuadernos de Universidades, Resumen ejecutivo. UDUAL, 2018.

RAMÍREZ, M. G.; BÉDARD, R. (2012). Reorientar el desempeño de la organización universitaria: una visión alternativa. EN BARBA, A. A.; LOBATO, O. C. (coords.), Instituciones de educación superior, políticas públicas y organización, México: UAM-I, Porrúa, 2012, 171- 204.

RAMÍREZ, M. G., VARGAS, G.; DE LA ROSA, A. Estudios Organizacionales y Administración. Contrastes y complementariedades: caminando hacia el eslabón perdido. Forum Doctoral, 3 , 2011, 7-53.

RAMÍREZ, M.G.; GONZALES-MIRANDA. Introducción. R. GONZALES-MIRANDA; G. RAMÍREZ, M. (eds.). Tratado de Estudios Organizacionales Volumen 2 Exploración de las temáticas. Editorial EAFIT Universidad Autónoma Latinoamericana, Red Mexicana de Investigadores en Estudios Organizacionales, London: Sage, 2019.

RAMÍREZ, T. De las crisis coyunturales a las crisis estructurales. La universidad a debate a propósito de los 100 años de Córdoba, Educere, 23(74), 2019, 123-128.

RAMOS, L.L.L.; CADENA, L.A. Estrategias metodológicas en los Estudios Organizacionales para el estudio de las organizaciones de educación superior. En G. RAMÍREZ, J.E.; ROSAS, 0.; LOZANO. C. (coord.) Realidades organizacionales e institucionales de México y Latinoamérica: Perspectivas de análisis. 950-989. México: HESS, 2018. 
REED, M. Organizational Analysis as a Discourse Analysis: A Critique. En GRANT, D.; KEENOY, T.; OSWICK, C. (coord.), Discourse and Organization, London: Sage, 1998, 193-213.

REED, M. Organizations and Modernity: Continuity and Discontinuity in organization Theory. En HASSARD, J.; PARKER, M. (coord.), Postmodernism and Organizations, Londres: Sage, 1993, 163-182.

RHOADES, G.; MALDONADO-MALDONADO; A. ORDORIKA, I.; VELAZQUEZ, M. Imagining Alternativas to Global, Corporate, New Economy Academic Capitalism. Policy Futures in Education, 2(2), 2004, 316-329.

SAMACA, A.G.D.; ACEVEDO, T.A. De la reforma de Córdoba al Cordobazo. La universidad como escenario de las luchas por la democracia en Argentina, 1918-1969 y su impacto en Colombia. Revista Digital de Historia y Arqueología desde el Caribe, (15), 2011, 170-195.

SANABRIA, M.; SAAVEDRA, J.J.; SMIDA, A. Los Estudios Organizacionales, Fundamentos, Evolución y Estado Actual del Campo. Bogotá: Editorial Universidad del Rosario, 2013.

SCHEIN, E. Organizational culture and leadership. San Francisco: Jossey-Bass, 2004.

SMIRCICH, L. Concepts of Culture and Organizational Analysis. Science Quarterly, 28(3), 1983, 339-358.

SOLÍS, P. Universidad, organización y sociedad. Saberes organizacionales: alcances y limitaciones de la certificación. EN BARBA Á. A.; L. MONTAÑO H. (coord.), Universidad, Organización y Sociedad: arreglos y controversias, México: UAM, Porrúa, 2001, 133-161.

SZLECHTER, D.; SOLARTE, P.L.; TEIXEIRA, J.C.; FEREGRINO, J.; MADARIAGA, P.I.; ALCADIPANI, R. Estudios organizacionales en América Latina: Hacia una agenda de investigación. RAE, 60(2), 2020, 84-92.

TÜNNERMAN, B.C. Desafíos de la Universidad en la Sociedad del Conocimiento, Cinco Años Después de la Conferencia Mundial sobre Educación Superior. UNESCO, 2003.

TÜNNERMAN, B.C. La educación superior en el umbral del siglo XXI. México: Ediciones CRESALC/UNESCO, 1998.

TÜNNERMAN, B.C. La educación superior frente a los desafíos contemporáneos. Asociación Colombiana de Universidades, 2011.

VAN DE VEN A.; POOLE, S. Explaining development and change in organizations. Academic of Management Review, 20(3), 1995, 510-540.

VÁZQUEZ W.; URBIOLA. El género como una perspectiva para el análisis de las organizaciones. Iztapalapa, 77(55), 2014. 159-189. 
VILLANUEVA, E. Perspectivas de la educación superior en América Latina: Construyendo futuros. Revista de la Educación Superior, 2010.

VILLASEÑOR, G. La función social de la educación superior en México. La que es y la que queremos que sea. México: UAM-X, 2003.

VILLAVERDE, R.M.J. Spinoza: homo homini Deus. Co-herencia, 15(28), 299-320.

WAGGONER, G.R. La Educación Superior en Estados Unidos y en Latinoamérica. Revista de la Educación Superior, 3(11), 1974, 1-14.

WEICK, K. Educational Organizations as Loosely Coupled Systems. Administrative Science Quarterly, 1(21), 1976, 1-19.

WITTEN, M. Narrativa y cultura de la obediencia en el lugar de trabajo. En Mumby, D., Narrativa y control social. Perspectivas críticas, Buenos Aires: Amorrortu, 1977, 132-160. 